\title{
ON THE USE OF ANTIBIOTICS FOR ISOLATING BACTERIA-FREE CULTURES OF MARINE PHYTOPLANKTON ORGANISMS
}

\author{
By C. P. Spencer \\ Marine Biological Station, University College of North Wales. \\ From the Plymouth Laboratory
}

(Text-fig. I)

In the course of some studies on the kinetics of growth and the biochemical activities of a marine diatom it became desirable to obtain bacteria-free cultures. The classical method of obtaining such pure algal cultures involves either repeatedly washing single cells in sterile medium or obtaining discrete bacteria-free algal colonies by growth on a solid medium. Both these methods have been widely applied to fresh-water species by Pringsheim (1946) and others, whilst Chu (I946) has used both methods with the marine diatom Nitzschia closterium (Ehrenberg) Wm. Smith forma minutissima.

The bacteria associated with algae (especially diatoms) are normally very tenaciously attached, and some (e.g. the blue-green algae) may penetrate the gelatinous sheaths. This characteristic of the bacteria may make a washing procedure impractical. Chu found it necessary to make a minimum of six initial subcultures in sterile medium under conditions that favoured algal rather than bacterial growth (low organic content of medium, high light intensity and low temperature) before selecting single cells for washing in sterile medium. It seems probable, therefore, that the washing technique will remove free-living but not attached bacteria (cf. the results of Zobell \& Allen (I935), who showed that more than half the bacteria in the sea will attach themselves to solid surfaces so tenaciously as to resist being washed off with running water). The plating technique does not seem to be widely applicable to marine species. Some thirty species have been tried during the present studies including representatives of the groups Cryptophyceae, Chrysophyceae, Chlorophyceae, Dinophyceae and Bacillariophyceae. Only two of the Chlorophyceae (Chlorella sp. and Chlamydomonas sp.) and one Bacillariophyceae (Nitzschia closterium f. minutissima) grew on Erdschreiber medium solidified with I. $5 \%$ agar. Numerous workers have investigated chemical and physical treatments in the hope of finding one that is bactericidal and which is tolerated by algae. Zobell has attempted to use heat, ultraviolet irradiation and various chemical bactericidal compounds (Zobell \& Long, I938). Of the latter acriflavine proved to be bacteriostatic in concentrations that did not 
greatly interfere with the growth of diatoms. Similarly, Gerloff, Fitzgerald \& Skoog (1950) have used ultraviolet irradiation to obtain bacteria-free cultures of the blue-green algae. Both these methods, however, depend upon a subsequent extinction dilution procedure.

The use of antibiotics seemed to offer a possible method. Fish (I950) employing exposure to massive doses of penicillin made some preliminary experiments with a green flagellate and an Enteromorpha culture. He was able to show that pre-treatment of the algae in 5000 units $/ \mathrm{ml}$. penicillin followed by subculture into a peptone broth (at a resultant concentration of 500 units of penicillin per ml.) prevented the growth of the bacterial flora for periods of up to 7 days and that the motility of the flagellate in Erdschreiber medium was apparently not affected by the presence of 1000 units $/ \mathrm{ml}$. of penicillin. In addition, by holding zoospores of Enteromorpha in a similar massive concentration of penicillin he was able to obtain a culture with no free-living bacteria in the medium. The flagellate was not subcultured in the absence of penicillin and subsequently tested for sterility nor was the algal material of the Enteromorpha submitted to sterility tests. In principle, however, the method seemed to offer a possible technique and these notes report some further work which has been directed towards extending the previous studies.

This work has been done in the laboratories of the Marine Biological Association at Plymouth. I wish to record my thanks to Mr F. S. Russell, F.R.S., for making freely available all the facilities of the laboratory, to Dr H. W. Harvey, F.R.S. and Dr Mary Parke for their continued interest and encouragement and for many helpful discussions and to the latter for supplying the cultures of phytoplankton organisms.

\section{Materials}

\section{EXPERIMENTAL}

Penicillin was obtained in a sterile condition as the crystalline sodium salt of $90 \%$ purity. Powdered sterile streptomycin (calcium chloride) was used. Solutions of required strength were made up in sterile water with aseptic precautions immediately before use.

\section{Bacteriological Methods}

Several media have been used for sterility testing. Their composition is detailed below.

Peptone sea water: $0.5 \%$ bacto-peptone, $0.01 \%$ ferric phosphate dissolved in $75 \%$ sea water.

Peptone sea water agar: as for peptone sea water plus $\mathrm{I} \cdot 5 \%$ powdered agar.

Casein sea water agar: $0.05 \%$ bacto-peptone, $0.05 \%$ soluble casein, $0.05 \%$ soluble starch, $0 . \mathrm{I} \%$ (v/v) glycerol, $0.02 \%$ dipotassium hydrogen phosphate, $\mathrm{I} \cdot 5 \%$ agar dissolved in $75 \%$ sea water. 
The media were made up in aged filtered sea water diluted to $75 \%$ with distilled water and were sterilized by autoclaving for $30 \mathrm{~min}$. at $5 \mathrm{lb}$. pressure.

Plate cultures were inoculated by pouring, care being taken to cool the agar to $42^{\circ} \mathrm{C}$. before addition. All cultures were incubated at $22^{\circ} \mathrm{C}$.

\section{Phytoplankton Cultures}

Throughout these studies, normal bacteriological techniques were used to prevent contamination. Organisms were cultured in either plugged $100 \mathrm{ml}$. conical Pyrex flasks or plugged $25 \times 150 \mathrm{~mm}$. rimless Pyrex tubes.

The Nitzschia closterium forma minutissima used in these studies was a subculture from Allen's original strain which had been maintained in Miquel medium. The other organisms were obtained by subculture from stocks maintained in normal Erdschreiber medium.

During these experiments the Nitzschia was maintained in sterile enriched sea water. This was prepared by diluting aged filtered sea water to $75 \%$ with distilled water and enriching with $30 \mathrm{mg}$. nitrogen (as sodium nitrate) and $20 \mu \mathrm{g}$. manganese (as manganese sulphate) per litre. This was sterilized by autoclaving for $30 \mathrm{~min}$. at $5 \mathrm{lb}$. pressure. After cooling it was further enriched with $3 \mathrm{mg}$. phosphorus (as disodium hydrogen phosphate), $8 \mathrm{mg}$. silica (as sodium silicate), and I00 $\mu \mathrm{g}$. iron (as ferric citrate: Rhoda, I948) per litre. The latter additions were made aseptically from sterile solutions of the required strength.

Other organisms were cultured in sterile Erdschreiber medium prepared by enriching $75 \%$ sea water with $0.03 \%$ sodium nitrate and, after sterilizing as above, enriching aseptically with $0.003 \%$ disodium hydrogen phosphate and $5 \%(\mathrm{v} / \mathrm{v})$ soil extract. The latter was prepared by extracting soil with an equal weight of water by heating in the autoclave for $30 \mathrm{~min}$. at $\mathrm{Io} \mathrm{lb}$. pressure. After clarifying the extract by centrifuging it was finally sterilized by autoclaving for $\mathrm{I} 5 \mathrm{~min}$. at $30 \mathrm{lb}$.

\section{The Observations}

At low concentrations penicillin is essentially bacteriostatic towards those bacteria which depend, for growth, upon the assimilation of glutamic acid rather than upon its synthesis. Such organisms tend to be Gram positive whereas the majority of marine bacteria are Gram negative (Zobell, I946). The technique of exposure for short periods to massive doses of antibiotic seemed to presuppose that under these conditions it may exert some bactericidal effect. There is some evidence that penicillin exerts a killing effect and may disorganize the ribonucleic acid metabolism of the cell (for references on mode of action of penicillin see review by Peck \& Lyons, I95I), but unfortunately the sterility tests used by Fish were conducted in the presence of a concentration of antibiotic that might, in any case, be expected to be bacteriostatic. Information was therefore required on the persistence of the 
antibiotic effect of penicillin (or its breakdown products) in sea water. Varying amounts of penicillin were added to sterile peptone sea water and stored in the light at room temperature. Inoculation of these with I ml. of a crude diatom culture at intervals showed that after I6 days' storage the inhibitory effect on bacterial growth of the original additions of Io० units $/ \mathrm{ml}$. was still very considerable.

Bearing these results in mind the effect of various concentrations of penicillin on the growth in peptone sea water of the bacterial flora associated with a crude diatom culture was investigated. The results shown in Table I are typical of those obtained.

\section{Table I. Effect of Penicillin on the Growth in Peptone Sea Water of the Bacterial Flora Associated with a Diatom Culture

$\begin{array}{cc}\begin{array}{c}\text { Concentration } \\ \text { of penicillin } \\ \text { (units/ml.) }\end{array} & \begin{array}{c}\text { Days incubation } \\ \text { before growth } \\ \text { first visible } \\ \text { (turbidity) }\end{array} \\ \text { Nil } & 2 \\ 5 & 3 \\ \text { I0 } & 4 \\ 50 & 8 \\ 100 & >21 \\ 500 & >21 \\ 1000 & >21\end{array}$

To tubes of peptone sea water were added various concentrations of penicillin. Tubes inoculated with I ml. of a crude culture of Nitzschia closterium. Observed daily and day when growth first seen in each tube (turbidity) noted.

Concentrations of 100 units $/ \mathrm{ml}$. and over inhibited bacterial growth in this medium for over 3 weeks. The correspondence between these results and those obtained by Fish on a sample of sea water suggests that pre-treatment for a limited period in high concentrations of penicillin has little additional effect and that the inhibition he observed is explicable in terms of the bacteriostatic effect of the penicillin present during his sterility tests.

The results with the higher penicillin concentrations offered some hope that the prolonged bacteriostatic effect would prevent survival of the bacterial flora without adversely affecting the diatoms. Samples of a vigorously growing culture of Nitzschia closterium forma minutissima were dispensed in plugged sterile tubes and amounts of penicillin added to give resultant concentrations of 50, 100, 500, 1000, 5000, and 10,000 units $/ \mathrm{ml}$. The cultures were kept in a north window. In those containing 5000 and 10,000 units $/ \mathrm{ml}$. diatom growth was obviously inhibited, the cells settling and finally loosing all colour. The diatoms in the lower concentrations grew well and showed no obvious difference from a control culture and were, after I6 days, still viable on subculturing to penicillin-free media. At the same time as this diatom viability test, one ml. samples of all tubes showing diatom growth were inoculated into $(a)$ peptone sea water, and $(b)$ peptone sea water agar. The results of this test 
are shown in Table II and indicate the essentially bacteriostatic action of the penicillin. Thus, though roo units penicillin per ml. is sufficient to inhibit all growth in peptone sea water for over 2I days, some bacterial cells are still viable and will grow on subculture to penicillin-free peptone sea water. The negative results obtained in peptone sea water on inoculation with samples from the diatom culture which had contained rooo units $/ \mathrm{ml}$. might be due to sufficient residual antibiotic activity having been carried over with the inoculum. On the other hand, on reinoculation of this tube some growth was obtained. Moreover, these penicillin concentrations yielded positive results when samples were used to inoculate peptone sea water agar. The same

Table II. Effect of Penicillin on the Survival of the Bacterial Flora Associated with a Growing CUlture of NITZSCHIA CLOSTERIUM

\begin{tabular}{|c|c|c|}
\hline \multirow{2}{*}{$\begin{array}{l}\text { Penicillin concentration } \\
\text { in diatom culture } \\
\text { (units } / \mathrm{ml} \text {.) }\end{array}$} & \multicolumn{2}{|c|}{ Bacterial growth } \\
\hline & P.s.w. & P.s.W.A. \\
\hline 50 & + & $\stackrel{+}{+}$ \\
\hline IOO & + & $\stackrel{+}{\text { (Heavy) }}$ \\
\hline 500 & + & $\stackrel{+}{\stackrel{+}{(S l i g h t})}$ \\
\hline 1000 & - & (Slight) \\
\hline
\end{tabular}

I ml. quantities of a diatom culture which had grown for I6 days in the presence of stated amounts of penicillin inoculated into (a) peptone sea water (P.s.w.), and (b) peptone sea water agar (P.S.W.A.).

dilution factor was involved in this case and it seems most probable that the prolonged bacteriostatic effect of the penicillin is sufficient to prevent survival of the majority of the bacterial flora which will grow easily in peptone sea water. Some cells of the flora survive and continue to grow on transference to a penicillin free media. These 'resistant cells' seem to be culturally different from the bulk of the flora in that they will not easily grow in peptone sea water but do so in an identical medium solidified with agar.

A similar series of experiments with streptomycin showed that this antibiotic was not as effective a bacteriostatic agent for the bacterial flora associated with a diatom culture as penicillin (see Tables III, IV and Fig. I). It was, moreover, more inhibitory to diatom growth, 500 units $/ \mathrm{ml}$. producing a marked inhibition. A comparison of the gross cultural characteristics of the 'streptomycin resistant' bacteria on peptone sea water agar showed a marked predominance of orange- or brown-pigmented colonies. In contrast, these organisms were sparsely distributed amongst the colonies that survived prolonged penicillin exposure. This suggested that the two antibiotics might be active against different sections of the bacterial flora and the possibility of the use of mixtures of the two was therefore investigated. A vigorously growing culture of Nitzschia closterium forma minutissima was dispensed in 
Table III. Effect of Streptomycin on the Growth in Peptone Sea Water of the Bacterial Flora Associated with a Diatom Culture

$\begin{array}{cr}\begin{array}{c}\text { Concentration of } \\ \text { streptomycin } \\ \text { (units/ml.) }\end{array} & \begin{array}{c}\text { Days incu } \\ \text { before grow } \\ \text { visible (tur }\end{array} \\ \text { Nil } & 2 \\ 5 & 4 \\ \text { I0 } & 4 \\ 50 & 5 \\ \text { I00 } & 7 \\ 500 & \text { IO } \\ \text { I000 } & \text { II }\end{array}$

To tubes of peptone sea water were added various concentrations of streptomycin. Tubes inoculated with $\mathrm{I} \mathrm{ml}$. of a crude culture of Nitzschia closterium. Observed daily and day when growth first seen in each tube (turbidity) noted.

Table IV. EfFect of Streptomycin on the Survival of the Bacterial Flora Associated With a Growing Culture of NitZsCHIA CLOSTERIUM

Streptomycin concentration in diatom culture (units/ml.)

Bacterial growth

50
100
500
1000

P.s.w. P.S.W.A.

$\begin{array}{ll}+ & + \\ + & + \\ + & + \\ + & +\end{array}$

I ml. quantities of the diatom culture which had grown for I6 days in the presence of stated amounts of streptomycin inoculated into (a) peptone sea water (P.S.W.), and (b) peptone sea water agar (P.S.W.A.).

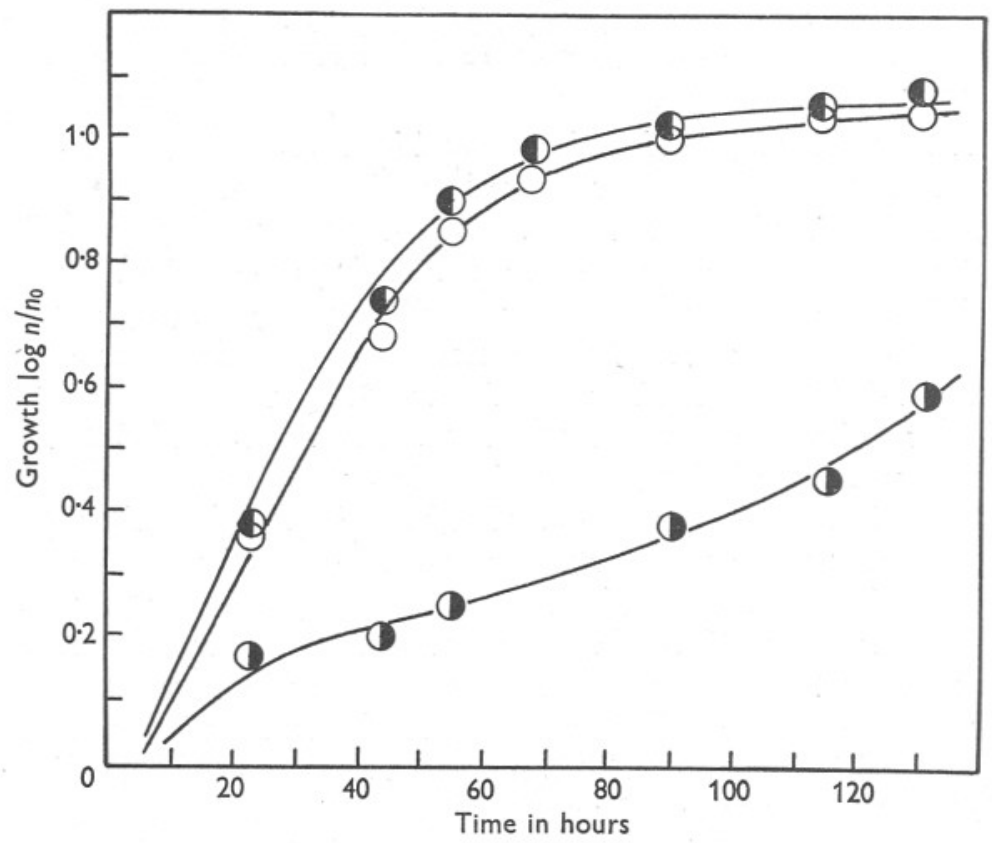

Fig. I. Growth of Nitzschia in enriched sea water (for details see text) with additions of antibiotics. Growth plotted as $\log n / n_{0}$, where $n_{0}=$ number of cells per $\mathrm{ml}$. at zero time and $n=$ the number at time $t$. - $-\mathrm{O}-\mathrm{O}-$, control (no antibiotic added); - D - D - , 500 units/ml. penicillin; - - -500 units/ml. streptomycin. 
plugged sterile tubes and penicillin and streptomycin added to give resultant concentrations of 50,100 and 500 units $/ \mathrm{ml}$. of both. The tubes were illuminated in a north window for I6 days during which time diatom growth occurred (somewhat inhibited in the highest concentration), all concentrations finally yielding viable diatom cells on subculture to antibiotic-free medium. At the same time I ml. quantities of the culture were tested for bacterial growth by inoculation into $(a)$ peptone sea water, and $(b)$ peptone sea water agar. The results are shown in Table V.

Table V. Effect of Penicillin and Streptomycin on the Survival of the Bacterial Flora Associated with a Growing Culture of NitzSchia CLOSTERIUM

$\begin{array}{ccc}\begin{array}{c}\text { Antibiotic } \\ \begin{array}{c}\text { concentration } \\ \text { units/ml. of both) } \\ 50\end{array}\end{array} & \begin{array}{c}\text { P.s.w. } \\ +\end{array} & \begin{array}{c}\text { P.s.w.A. } \\ + \\ \text { (Slight) }\end{array} \\ 500 & + & -\end{array}$

I ml. quantities of a diatom culture which had grown in the presence of stated amounts of both penicillin and streptomycin for I6 days inoculated into (a) peptone sea water (P.S.w.), and $(b)$ peptone sea water agar (P.s.w.A.).

The diatom cells grown in the presence of 500 units $/ \mathrm{ml}$. of both streptomycin and penicillin showed no bacterial growth after inoculation into both testing media. On reinoculation of these tests with I ml. of a crude diatom culture, only slight growth was obtained in peptone sea water and none on peptone sea water agar, and it therefore seems probable that the negative results obtained were due to residual antibiotic activity being carried over with the inoculum. Considerable numbers of diatom cells were still viable and good growth was obtained on inoculation into sterile enriched sea water without additions of the antibiotics. On repeating the same procedure with other samples of the same crude diatom culture, treatment with 500 units $/ \mathrm{ml}$. of the two antibiotics did not always yield completely negative sterility tests of the type shown in Table V. Regardless of this, the bacteriostatic effect of the antibiotics is always very considerable and providing a vigorous diatom growth has occurred the ratio of bacteria : diatoms will always have increased tremendously in favour of the diatoms. It has invariably been found possible to obtain a bacteria-free subculture of the diatom by inoculating numerous samples of sterile enriched sea water with very small inocula from the antibiotic treated culture (e.g. loop inocula of approximate volume $0.006 \mathrm{ml}$.). I ml. samples from a proportion of such subcultures normally prove to be bacteria-free. One such strain of Nitzschia has been maintained for several months by serial subculture in sterile medium. Regular sterility tests show it to be still bacteria-free.

A preliminary investigation has been made of the possibility of applying 
the technique to other phytoplankton cultures. Of numerous organisms tested only one Chrysophyceae (Chromulina pleiades Parke), one Dinophyceae (Peridinium trochoideum (Stein) Lemm.) and three Chlorophyceae (Chlorella sp., Chlamydomonas sp., and Stichococcus sp.) would grow in the presence of 500 units $/ \mathrm{ml}$. of penicillin and streptomycin. By dropping the streptomycin concentration to 100 units $/ \mathrm{ml}$. the growth of two other Chrysophyceae (Isochrysis galbiana Parke, and Flagellate 25 Plymouth), Prorocentrum micans Ehrenb. and Coccolithus huxleyi (Lohm.) Kamptner occurred. No members of the Cryptophyceae tested showed any growth except Hemiselmis rufescens Parke, which gave variable results. A feature of thèse latter investigations was the reluctance to grow on subculture from the antibiotic-treated culture to ordinary Erdschreiber of those members of the Dinophyceae and Chrysophyceae which had produced good growth in the presence of the antibiotics.

\section{DisCUSSION}

The preliminary investigations reported in this note indicate that the use of penicillin and streptomycin for obtaining bacteria-free cultures of diatoms depends upon their selective bacteriostatic action. It seems possible that the high concentrations used do exert some bactericidal effect, but some of the bacterial flora survives long exposure under these conditions. Success, therefore, depends upon some form of extinction dilution procedure, though under suitable conditions this can be reduced to the use of small inocula for subculture from the antibiotic-treated media.

It must be emphasized that sterility tests can give misleading results if there is a chance of sufficient antibiotic activity being carried over with the inocula, and in view of this such tests are best carried out on samples of subsequent subcultures in sterile antibiotic-free medium. In any case it is desirable that several successive subcultures in the absence of antibiotics should prove to be sterile before the culture is considered to be bacteria free. In addition, experience has shown the desirability of extensive sterility testing on a variety of media. Cultures have frequently been obtained which yielded no bacterial growth on peptone sea water agar but did in peptone sea water and vice versa. The casein medium has sometimes shown the presence of bacteria (and actinomycetes) which did not grow on either peptone sea water or peptone sea water agar. The latter medium (Zobell, I94I) seems, however, to satisfy the requirements of most marine heterotrophes and the use of both liquid and solid media for sterility testing appears more important than the use of media of widely differing nutrient composition.

The antibiotics used are not effective against moulds and actinomycetes and their addition in the quantities used causes an enhanced growth of such organisms. It is essential that the crude phytoplankton cultures used should be free of such organisms, otherwise the culture will be heavily contaminated 
with mycelial growth. Vigorously growing algal cultures are, however, normally only slightly contaminated with such organisms and a mould-free algal culture can normally be obtained by the usual washing procedure prior to antibiotic treatment. It is of interest that very heavy mycelial growth which occurred in some flagellate cultures treated with antibiotics did not cause any marked inhibition of algal growth.

Throughout these studies it has been obvious that organisms which best survived the antibiotic treatment were those of a robust nature (e.g. Nitzschia and members of the Chlorophyceae). In general these organisms are known to be non-exacting in their nutritional requirements and will grow in Miquel Sea Water. Organisms which need soil extract for continued growth are the most affected by the antibiotics. The organisms of this class, which will tolerate the action of the antibiotics, frequently do not grow on subsequent subculture to sterile antibiotic-free media. In such it is possible that the antibiotics have directly affected the algae. It seems more probable, however, that such effects are due to an indirect action. If the more nutritionally exacting algae are dependent upon symbiotic bacteria for essential nutrients or growth factors, then control of the bacterial flora may ultimately limit algal growth. Such considerations make the direct application of the technique to a wide variety of phytoplankton organisms difficult. For any organisms with complex nutritional requirements, media other than Erdschreiber may have to be used in the absence of the symbiotic bacteria.

\section{SUMMARY}

To develop a technique for the isolation of bacteria-free algal cultures, the use of penicillin and streptomycin for controlling bacterial growth has been investigated.

By using the selective bacteriostatic properties of the antibiotics it has been found possible to increase the ratio algal cells : bacteria markedly in favour of the algae. From suitably treated cultures it has been found possible to obtain subcultures of Nitzschia closterium forma minutissima and two members of the Chlorophyceae which produce no bacterial growth on a variety of media.

A preliminary investigation of the application of the technique to other algal cultures has been made. The possibilities and difficulties of this are discussed.

\section{REFERENCES}

CHU, S. P., 1946. Note on the technique of making bacteria-free cultures of marine diatoms. Fourn. Mar. Biol. Assoc., Vol. 19, pp. 755-9.

FISH, G. R., I950. A method of obtaining bacteria-free cultures of a marine flagellate and Enteromorpha intestinalis using penicillin. Maddelanden frän Gotebergs botaniska Trädgård, Bd. I8, pp. 82-9.

Gerloff, G. C., Fitzgerald, G. P. \& Skoog, F., I950. The isolation, purification, and nutrient solution requirements of blue green algae. In The Culturing of Algae. Ohio: Antioch Press. 
Peck, R. L. \& Lyons, J. E., I95I. Biochemistry of antibiotics. Ann. Rev. Biochem., Vol. 20, pp. 367-4I4.

Pringsheim, E. G., 1946. Pure Cultures of Algae. Cambridge University Press.

RHoDA, W., I948. Environmental requirements of fresh water plankton algae. Symbolae Botanicae Upsalienses, $\mathrm{x}, \mathrm{i}$. Uppsala.

ZobeLL, C. E., I94I. Cultural requirements of marine heterotrophic aerobes. Fourn. Mar. Research, Vol. 4, pp. 42-75.

Zobell, C. E., I946. Marine microbiology. Chronica Botanica. Waltham, Mass., U.S.A.

Zobell, C. E. \& Allen, E. C., I935. The significance of marine bacteria in the fouling of submerged surfaces. Fourn. Bact., Vol. 29, pp. 239-5I.

Zobell, C. E. \& LONG, J. H., I938. Studies on the isolation of bacteria-free cultures of marine phytoplankton. Fourn. Mar. Research, Vol. I, pp. 328-33. 